\title{
Predictors of positive CT scans in the elderly trauma patients with minor head injury. Case reports and review of the literature Nikolaos Syrmos*, Ilias Gramatikopoulos, Vasilios Valadakis, Konstantinos Grigoriou and Dimitrios Arvanitakis
}

Address: Neurosurgical Department-Venizeleio General Hospital, Heraklion, Crete

* Corresponding author

from International Society on Brain and Behaviour: 3rd International Congress on Brain and Behaviour

Thessaloniki, Greece. 28 November - 2 December 2007

Published: 17 April 2008

Annals of General Psychiatry 2008, 7(SuppI I):S302 doi:I0.I I86/I744-859X-7-SI-S302

This abstract is available from: http://www.annals-general-psychiatry.com/content/7/SI/S302

(C) 2008 Syrmos et al.; licensee BioMed Central Ltd.

\section{Background}

The purpose of this study was to determine whether there were characteristics of the trauma patient with a minor head injury. Glasgow Coma Scale (GCS) of 13-15, that would predict a positive cerebral CT scan.

\section{Materials and methods}

An analysis of 300 patients with potential head injuries transported to our department was performed. The following characteristics were analyzed as possible predictors: 1 . scene GCS, 2. emergency room GCS, 3. a change in GCS from scene to emergency room, 4 . loss of consciousness, 5. focal neurological deficit.

\section{Results}

50 per cent (150/300) of the patients underwent CT scanning of the head. CT scans were positive in 5,3 per cent $(16 / 300)$ of the total group and 10.6 per cent $(16 / 150)$ of those who underwent CT scanning. In the patients without LOC and ER-GCS of 13-15, all CT scans were negative.

\section{Conclusions}

Of all the patients with positive CT scans, 4 underwent emergent craniotomy: 2 for a depressed skull fracture with underlying contusion, and 2 for a temporal bone fracture and an epidural hematoma. Both patients had LOC and SC-GCS and ER-GCS of 15. We present our cases and finally we performed a review of the literature.

\section{References}

I. Livingston $\mathrm{DH}$, Loder PA, Hunt $\mathrm{CD}$ : Minimal head injury: is admission necessary? Am Surg. 199|, 57(1):14-7.

2. Borczuk P: Predictors of intracranial injury in patients with mild head trauma. Ann Emerg Med. 1995, 25(6):73I-6.

3. Dacey RG Jr, Alves WM, Rimel RW, Winn HR, Jane JA: Neurosurgical complications after apparently minor head injury. Assessment of risk in a series of 610 patients. J Neurosurg 1986, 65(2):203-10. 